\title{
Pharmacological Treatment of Obesity in Patients with Polycystic Ovary Syndrome
}

\author{
Hassan Kahal,, ${ }^{1,2}$ Stephen L. Atkin, ${ }^{1}$ and Thozhukat Sathyapalan ${ }^{1}$ \\ ${ }^{1}$ Academic Endocrinology, Diabetes and Metabolism, Hull York Medical School, Hull HU3 2RW, UK \\ ${ }^{2}$ Michael White Diabetes Centre, 220-236 Analby Road, Hull Royal Infirmary, Hull HU3 2JZ, UK
}

Correspondence should be addressed to Hassan Kahal, hassan.kahal@yahoo.co.uk

Received 20 April 2010; Revised 13 July 2010; Accepted 4 November 2010

Academic Editor: S. B. Heymsfield

Copyright ( $) 2011$ Hassan Kahal et al. This is an open access article distributed under the Creative Commons Attribution License, which permits unrestricted use, distribution, and reproduction in any medium, provided the original work is properly cited.

Polycystic ovary syndrome (PCOS) is a common disorder affecting women of reproductive age and it is associated with increased cardiovascular risk. Obesity plays an important role in the pathogenesis of PCOS, and the majority of patients with PCOS are obese. Over the last 20 years, the prevalence of obesity has dramatically increased, with probable associated increase in PCOS. Weight reduction plays an integral part in the management of women with PCOS. In this paper, current available weight reduction therapies in the management of PCOS are discussed.

\section{Introduction}

Polycystic ovary syndrome (PCOS) is a common disorder with a prevalence of $6-7 \%$ of women of reproductive age [1-4]. The clinical picture commonly includes obesity, hirsutism, oligomenorrhoea, and subfertility. Around 30-75\% of PCOS women are obese $[1,5,6]$, and many PCOS women show evidence of insulin resistance and hyperandrogenism. In 2003, the European Society for Human Reproduction and Embryology (ESHRE) and the American Society for Reproductive Medicine (ASRM) cosponsored the Rotterdam polycystic ovary syndrome consensus workshop that revised and broadened the National Institute of Health (NIH) 1990 diagnostic criteria [7].

While chronic anovulation with biochemical and/or clinical hyperandrogensim is essential for making the diagnosis under the NIH 1990, classic PCOS, [8] the revised Rotterdam criteria [7] (box 1) included women with hyperandrogenism but regular menses and those with menstrual disturbance without overt androgen excess, nonclassic PCOS. The revised Rotterdam criteria, although commonly, used are still controversial and reflect the heterogeneous presentation of the syndrome and the advances in understanding its uncertain aetiology [9].

\section{The Role of Obesity in the Development of PCOS}

The exact role that obesity plays in the development of PCOS remains to be determined. The theories that have been put forward to explain the metabolic abnormalities associated with obesity may also be applicable to explain the role of obesity in the development of PCOS.

The adipokine theory suggests that the adipose tissue is an endocrine organ that secretes several hormones (adipokines). Insulin resistance and hyperandrogenism are common features of PCOS $[7,10]$. Alteration in adipokines levels may lead to the development of PCOS. Adiponectin is exclusively produced by the adipose tissue [11]. Several studies have shown adiponectin to be lower in PCOS women when compared to weight-matched controls $[12,13]$. Adiponectin is inversely related to insulin resistance [14]. While some studies suggest a strong correlation between adiponectin and androgen levels in PCOS [13], others did not show similar association [12]. Leptin is not produced exclusively by adipocytes but its circulating levels are strongly correlated to adipose mass and are higher in obese people [15]. In most studies, leptin levels in PCOS were similar to those of controls of similar body weight [16]. Whether leptin 
Two of the following three criteria must be fulfilled:

(i) A clinical diagnosis of oligomenorrhoea or amenorrhoea

(ii) Clinical or biochemical evidence of hyperandrogenism

(iii) Polycystic ovaries on ultrasound examination (either 12 or more follicles measuring $2-9 \mathrm{~mm}$

in diameter, or an ovarian volume of $>10 \mathrm{~cm}^{3}$ )

Late onset congenital adrenal hyperplasia, androgen secreting tumours, and Cushing's syndrome must be excluded in women with raised androgens; thyroid disorders and raised prolactin should be excluded in women with menstrual disturbances.

Algorithm 1: Revised 2003 criteria for diagnosing polycystic ovary syndrome (PCOS) [7].

levels in PCOS are associated with androgen levels remains controversial $[17,18]$. Hyperleptinaemia has been associated with insulin resistance [17] and is inversely related to fertility in PCOS women [19]. Resistin is another adipokine and its relationship to PCOS remains debatable. Increased levels of resistin have been linked to the development of insulin resistance [20] and may play a role in the development of cardiovascular disease [21]. However, while some studies suggest increased levels in PCOS [16], others showed PCOS women to have similar levels when compared to weightmatched controls [13].

On the other hand, the adipose tissue expandability theory [22] proposes that at a set point of positive energy imbalance, which is determined on an individual basis by genetics and environmental factors, the subcutaneous adipose tissue fails to expand to store more fat subcutaneously. This results in a state of lipotoxicity and fat starts to deposit in other tissues like the liver, muscles, and pancreas. Lipotoxicity drives insulin resistance and subsequently hyperandrogenism commonly seen in PCOS women [23].

One of the difficulties that face any theory trying to explain the origin of PCOS is that it is not one entity. Women with PCOS are not all obese or insulin resistant [24], and the presence of hyperandrogenism and oligo/amenorrhoea is not necessary for making the diagnosis.

\section{Obesity and Cardiovascular Disease in PCOS}

Many cardiovascular (CV) risk factors are increased in PCOS even after adjusting for weight. For example, women with PCOS have impaired glucose tolerance [25], dyslipidaemia [26], endothelial [27] and platelets dysfunction [28], lower adiponectin [12], and higher homocysteine levels [18]. Despite the lack of long-term CV outcome data, it has been suggested that PCOS women have a sevenfold increase in relative risk for myocardial infarction [29], higher prevalence of cerebrovascular disease [30], and worsening CV event-free survival [31].

Obesity contributes to the $43 \%$ prevalence of the metabolic syndrome in PCOS patients [32]. Central obesity is often associated with PCOS [33] and carries increased risk for developing cardiovascular disease and type 2 diabetes [34].

Over the past 2 decades, the rate of obesity has raised threefold [25]. Whether there is an increase in the prevalence of PCOS to parallel the increase in obesity is still controversial $[35,36]$.

\section{Treatment of Obesity in the Setting of PCOS}

Even modest weight loss of less than $10 \%$ of initial body weight has been shown to increase the frequency of ovulation, improve conception, and reduce testosterone, free androgen index, hyperlipidaemia, hyperglycaemia, and insulin resistance in women with PCOS [37, 38].

4.1. Life Style Changes. Lifestyle modification is regarded as the first line treatment for women with PCOS. Exercise and weight loss improve insulin sensitivity. $44-57 \%$ of PCOS women had improvement in either menstrual cycle or ovulation after lifestyle changes and subsequent weight loss $[37,39,40]$. One of the main challenges of lifestyle changes is the low participants' compliance rate over time [39]. Therefore, pharmaceutical intervention is an additional essential therapeutic tool to lifestyle changes in many patients.

4.2. Medical Therapy. Few safe and effective drugs are currently available for the treatment of obesity. Although Sibutramine [41] and rimonabant [42] have been shown to be effective in inducing weight loss in PCOS women, they have both been withdrawn from the UK. Rimonabant increased the risk of psychiatric disorders and sibutramine has been associated with hypertension and cardiovascular disease.

4.2.1. Orlistat. Orlistat is a lipase inhibitor that reduces fat absorption in the gut by approximately $30 \%$ [43]. In a metaanalysis, it is estimated that orlistat treatment led to an average placebo-subtracted weight loss of $2.7 \mathrm{~kg}$ at 1 year [44]. In a 4-year randomised controlled trial of 3305 obese, nondiabetic patients, orlistat treatment was associated with a $3.6-\mathrm{kg}$ weight loss compared with $1.4 \mathrm{~kg}$ for placebo at 4 years [45].

In women with PCOS, a $4.69 \%$ weight reduction was reported with orlistat therapy with an associated improvement in total testosterone levels [46]. In a 12-week randomised open labelled study [47], orlistat reduced insulin resistance by around $20 \%$ and variability of insulin resistance by $40 \%$ in obese PCOS women. In a 6-month clinical trial, therapeutic intervention with orlistat and a low-calorie diet 
resulted in a beneficial effect in PCOS in reducing advanced glycation end-products (AGE) levels and testosterone concentrations independently of BMI changes [48].

The use of orlistat is limited by its gastrointestinal side effects. Approximately, 15-30\% of those taking orlistat experience oily stool, faecal urgency, or oily spotting, and 7\% report faecal incontinence, particularly at the initiation of treatment [44]. Despite its relatively high rate of side effects, orlistat is a useful treatment tool in the management of obese PCOS women.

4.2.2. Metformin. Metformin is a biguanide commonly used for the treatment of type 2 diabetes. Metformin's primary action is on the liver, where it reduces gluconeogenesis. Extrahepatic sites of action include the skeletal muscles, adipose tissue, endothelium, and the ovary $[49,50]$. Metformin is commonly used in women with PCOS and is reported to improve insulin resistance, sex hormone binding globulin (SHBG), hyperandrogenaemia, and ovulation [51, 52 ]. Metformin's effect on weight management remains controversial. In a small $(n=56)$ randomized, double-blinded, placebo controlled cross-over study, 6-month treatment with Metformin resulted in mean weight reduction of $2.3 \mathrm{~kg}$ $(P<.009)$ [53]. However, in a systematic review and metaanalysis [54], metformin was found to have no effect on body weight and body mass index (BMI) in women with PCOS. Metformin may be more effective in subgroups of PCOS women and at higher doses. Nonobese women with PCOS responded better to metformin than obese women with regards to insulin sensitivity, free testosterone, and androstendione concentrations [55]. Metformin was also found to cause a dose-related weight loss in obese women with PCOS [56], (1.5 and $3.6 \mathrm{~kg}$ weight loss in 1500- and $2550-\mathrm{mg}$ /day metformin treated groups, resp.). Metformin when given to obese PCOS women after rimonabant, an endocannabinoid blocker, maintained the weight reduction and decrease in waist circumference achieved by rimonabant and augmented the initial improvements in testosterone levels and insulin resistance [57]. It is possible that the insulin sensitisation action of metformin was complementary to the weight loss caused by rimonabant.

Most frequent side effects of metformin are gastrointestinal symptoms including nausea, anorexia, vomiting, abdominal discomfort, and diarrhoea and occur in up to $20 \%$ of patients. In $3-5 \%$ patients, therapy may have to be discontinued because of these adverse effects $[50,58]$. Slow release forms of metformin are available and are believed to be better tolerated.

Despite the lack of strong evidence, the use of metformin in obese PCOS women is likely to be beneficial especially when taken at higher doses.

4.2.3. Incretin Mimetics Therapy. The gastrointestinal tract produces several peptide hormones that participate in regulation of food intake. Ingested nutrients, especially fats and carbohydrates, stimulate Glucagon-like peptide- 1 (GLP-1) secretion from L cells in the distal small intestine [59]. GLP-1 accentuates glucose-dependent insulin release, inhibits glucagon secretion, increases pancreatic $\beta$ cell growth, suppresses appetite and energy intake, and delays gastric emptying [60-63]. Glucagon-like peptide-1 receptor (GLP-1R) is expressed by the gut, pancreas, brainstem, hypothalamus, and vagal-afferent nerves [60]. Activation of the hypothalamic GLP-1R decreases food intake [64].

In a 24-week randomised controlled trial in women with PCOS [65], a combination treatment with exenatide (GLP1 mimetic) and metformin was found to be superior to exenatide or metformin monotherapy in reducing weight (mean weight loss of $6 \pm 0.5 \mathrm{~kg}$ ) and improving menstrual cycles, ovulation rate, free androgen index, and insulin sensitivity.

In another 20-week randomised open labelled study involving obese people without PCOS [66], comparing liraglutide (GLP1 analogue) to orlistat, it was shown that liraglutide treatment is well tolerated and induced significant dose-related weight loss (mean weight loss $4.8-7.2 \mathrm{~kg}$ ) compared to placebo or orlistat. All the patients were obese and had a $500 \mathrm{kcal}$ per day energy deficit diet and increased their physical activity throughout the study.

In a head-to-head comparison study in people with type 2 diabetes, $1.8 \mathrm{mg}$ liraglutide daily and $10 \mu \mathrm{g}$ exenatide twice daily produced similar weight loss $(3.2 \mathrm{~kg}$ with liraglutide versus $2.9 \mathrm{~kg}$ with exenatide) [67]. However, liraglutide achieved better glycaemic control and was better tolerated than exenatide [67].

Most commonly reported side effects are nausea and vomiting, but the main safety concern remains a possible increased risk of pancreatitis attributable to drugs that act through the GLP-1 pathway [68]. One of the disadvantages of using GLP-1R agonists is that they require injection. Although, not yet licensed for obesity management, GLP-1R agonists offer a potential obesity treatment for women with PCOS.

4.2.4. Bariatric Surgery. In subjects with morbid obesity, bariatric surgery may be considered as an effective therapy. Few studies have shown bariatric surgery to be associated with significant improvement in weight, hirsutism, insulin resistance, and fertility in women with PCOS $[69,70]$.

\section{Conclusions}

PCOS is a common disorder of uncertain aetiology. It is associated with increased cardiovascular morbidity. Obesity plays an important part in the pathogenesis of PCOS. Many PCOS women are obese, and weight reduction is an essential part in their management.

In the management of obese women with PCOS, lifestyle modification is the first step although low long-term compliance rate may reduce benefit. Orlistat, with dietary changes, is beneficial despite its common gastrointestinal side effects. Metformin, at higher doses, may promote weight loss. Although not currently licensed, newer pharmacotherapeutic agents like incretin mimetics hold promise in managing obese women with PCOS. 


\section{References}

[1] R. Azziz, K. S. Woods, R. Reyna, T. J. Key, E. S. Knochenhauer, and B. O. Yildiz, "The prevalence and features of the polycystic ovary syndrome in an unselected population," Journal of Clinical Endocrinology and Metabolism, vol. 89, no. 6, pp. 2745-2749, 2004.

[2] E. S. Knochenhauer, T. J. Key, M. Kahsar-Miller, W. Waggoner, L. R. Boots, and R. Azziz, "Prevalence of the polycystic ovary syndrome in unselected black and white women of the Southeastern United States: a prospective study," Journal of Clinical Endocrinology and Metabolism, vol. 83, no. 9, pp. 3078-3082, 1998.

[3] E. Diamanti-Kandarakis, C. R. Kouli, A. T. Bergiele et al., "A survey of the polycystic ovary syndrome in the Greek Island of Lesbos: hormonal and metabolic profile," Journal of Clinical Endocrinology and Metabolism, vol. 84, no. 11, pp. 4006-4011, 1999.

[4] M. Asunción, R. M. Calvo, J. L. San Millá N, J. Sancho, S. Avila, and H. F. Escobar-Morreale, "A prospective study of the prevalence of the polycystic ovary syndrome in unselected Caucasian women from Spain," Journal of Clinical Endocrinology and Metabolism, vol. 85, no. 7, pp. 2434-2438, 2000.

[5] A. H. Balen, G. S. Conway, G. Kaltsas et al., "Polycystic ovary syndrome: the spectrum of the disorder in 1741 patients," Human Reproduction, vol. 10, no. 8, pp. 2107-2111, 1995.

[6] C. J. Glueck, S. Dharashivkar, P. Wang et al., "Obesity and extreme obesity, manifest by ages 20-24 years, continuing through 32-41 years in women, should alert physicians to the diagnostic likelihood of polycystic ovary syndrome as a reversible underlying endocrinopathy," European Journal of Obstetrics Gynecology and Reproductive Biology, vol. 122, no. 2, pp. 206-212, 2005.

[7] B. C. J. M. Fauser, . Tarlatzis, . Fauser et al., "Revised 2003 consensus on diagnostic criteria and long-term health risks related to polycystic ovary syndrome," Human Reproduction, vol. 19, no. 1, pp. 41-47, 2004.

[8] J. K. Zawadzki and A. Dunaif, "Diagnostic criteria for polycystic ovary syndrome: towards a rational approach," in Polycystic Ovary Syndrome, A. Dunaif, J. R. Givens, F. P. Haseltine, and G. R. Merriam, Eds., pp. 59-69, Blackwell, Oxford, UK, 1992.

[9] S. Franks, "Diagnosis of polycystic ovarian syndrome: in defense of the Rotterdam criteria," Journal of Clinical Endocrinology and Metabolism, vol. 91, no. 3, pp. 786-789, 2006.

[10] A. Dunaif, K. R. Segal, W. Futterweit, and A. Dobrjansky, "Profound peripheral insulin resistance, independent of obesity, in polycystic ovary syndrome," Diabetes, vol. 38, no. 9, pp. 1165$1174,1989$.

[11] P. E. Scherer, S. Williams, M. Fogliano, G. Baldini, and H. F. Lodish, "A novel serum protein similar to $\mathrm{C} 1 \mathrm{q}$, produced exclusively in adipocytes," Journal of Biological Chemistry, vol. 270, no. 45, pp. 26746-26749, 1995.

[12] K. A. Toulis, D. G. Goulis, D. Farmakiotis et al., "Adiponectin levels in women with polycystic ovary syndrome: a systematic review and a meta-analysis," Human Reproduction Update, vol. 15, no. 3, pp. 297-307, 2009.

[13] A. O’Connor, N. Phelan, T. Kyaw Tun, G. Boran, J. Gibney, and H. M. Roche, "High-molecular-weight adiponectin is selectively reduced in women with polycystic ovary syndrome independent of body mass index and severity of insulin resistance," Journal of Clinical Endocrinology and Metabolism, vol. 95, no. 3, pp. 1378-1385, 2010.
[14] C. Weyer, T. Funahashi, S. Tanaka et al., "Hypoadiponectinemia in obesity and type 2 diabetes: close association with insulin resistance and hyperinsulinemia," Journal of Clinical Endocrinology and Metabolism, vol. 86, no. 5, pp. 1930-1935, 2001.

[15] C. S. Mantzoros, "The role of leptin in human obesity and disease: a review of current evidence," Annals of Internal Medicine, vol. 130, no. 8, pp. 671-680, 1999.

[16] E. Carmina, F. Orio, S. Palomba et al., "Evidence for altered adipocyte function in polycystic ovary syndrome," European Journal of Endocrinology, vol. 152, no. 3, pp. 389-394, 2005.

[17] D. Glintborg, M. Andersen, C. Hagen et al., "Evaluation of metabolic risk markers in polycystic ovary syndrome (PCOS). Adiponectin, ghrelin, leptin and body composition in hirsute PCOS patients and controls," European Journal of Endocrinology, vol. 155, no. 2, pp. 337-345, 2006.

[18] A. Atamar, B. Demir, G. Bayhan, Y. Atamer, N. Ilhan, and Z. Akkuş, "Serum levels of leptin and homocysteine in women with polycystic ovary syndrome and its relationship to endocrine, clinical and metabolic parameters," Journal of International Medical Research, vol. 36, no. 1, pp. 96-105, 2008.

[19] M. G. Li, G. L. Ding, XI. J. Chen et al., "Association of serum and follicular fluid leptin concentrations with granulosa cell phosphorylated signal transducer and activator of transcription 3 expression in fertile patients with polycystic ovarian syndrome," Journal of Clinical Endocrinology and Metabolism, vol. 92, no. 12, pp. 4771-4776, 2007.

[20] C. M. Steppan, S. T. Bailey, S. Bhat et al., "The hormone resistin links obesity to diabetes," Nature, vol. 409, no. 6818, pp. 292-293, 2001.

[21] H. Mu, R. Ohashi, S. Yan et al., "Adipokine resistin promotes in vitro angiogenesis of human endothelial cells," Cardiovascular Research, vol. 70, no. 1, pp. 146-157, 2006.

[22] S. Virtue and A. Vidal-Puig, "It's not how fat you are, it's what you do with it that counts," PLoS Biology, vol. 6, no. 9, article e237, 2008.

[23] F. de Zegher, A. Lopez-Bermejo, and L. Ibáñez, "Adipose tissue expandability and the early origins of PCOS," Trends in Endocrinology and Metabolism, vol. 20, no. 9, pp. 418-423, 2009.

[24] D. Meirow, O. Yossepowitch, A. Rosler et al., "Insulin resistant and non-resistant polycystic ovary syndrome represent two clinical and endocrinological subgroups," Human Reproduction, vol. 10, no. 8, pp. 1951-1956, 1995.

[25] D. A. Ehrmann, M. K. Cavaghan, R. B. Barnes, J. Imperial, and R. L. Rosenfield, "Prevalence of impaired glucose tolerance and diabetes in women with polycystic ovary syndrome," Diabetes Care, vol. 22, no. 1, pp. 141-146, 1999.

[26] E. Talbott, D. Guzick, A. Clerici et al., "Coronary heart disease risk factors in women with polycystic ovary syndrome," Arteriosclerosis, Thrombosis, and Vascular Biology, vol. 15, no. 7, pp. 821-826, 1995.

[27] E. Diamanti-Kandarakis, K. Alexandraki, A. Protogerou et al., "Metformin administration improves endothelial function in women with polycystic ovary syndrome," European Journal of Endocrinology, vol. 152, no. 5, pp. 749-756, 2005.

[28] S. Rajendran, S. R. Willoughby, W. P. A. Chan et al., "Polycystic ovary syndrome is associated with severe platelet and endothelial dysfunction in both obese and lean subjects," Atherosclerosis, vol. 204, no. 2, pp. 509-514, 2009.

[29] E. Dahlgren, P. O. Janson, S. Johansson, L. Lapidus, and A. Oden, "Polycystic ovary syndrome and risk for myocardial infarction: evaluated from a risk factor model based on 
a prospective population study of women," Acta Obstetricia et Gynecologica Scandinavica, vol. 71, no. 8, pp. 599-604, 1992.

[30] S. Wild, T. Pierpoint, P. McKeigue, and H. Jacobs, "Cardiovascular disease in women with polycystic ovary syndrome at long- term follow-up: a retrospective cohort study," Clinical Endocrinology, vol. 52, no. 5, pp. 595-600, 2000.

[31] L. J. Shaw, C. N. B. Merz, R. Azziz et al., "Postmenopausal women with a history of irregular menses and elevated androgen measurements at high risk for worsening cardiovascular event-free survival: results from the National Institutes of Health-National Heart, Lung, and Blood Institute sponsored women's ischemia syndrome evaluation," Journal of Clinical Endocrinology and Metabolism, vol. 93, no. 4, pp. 1276-1284, 2008.

[32] T. Apridonidze, P. A. Essah, M. J. Iuorno, and J. E. Nestler, "Prevalence and characteristics of the metabolic syndrome in women with polycystic ovary syndrome," Journal of Clinical Endocrinology and Metabolism, vol. 90, no. 4, pp. 1929-1935, 2005.

[33] T. Douchi, H. Ijuin, S. Nakamura, T. Oki, S. Yamamoto, and Y. Nagata, "Body fat distribution in women with polycystic ovary syndrome," Obstetrics and Gynecology, vol. 86, no. 4, part 1, pp. 516-519, 1995.

[34] P. Acien, F. Quereda, P. Matallin et al., "Insulin, androgens, and obesity in women with and without polycystic ovary syndrome: a heterogeneous group of disorders," Fertility and Sterility, vol. 72, no. 1, pp. 32-40, 1999.

[35] F. Álvarez-Blasco, J. I. Botella-Carretero, J. L. San Millán, and H. F. Escobar-Morreale, "Prevalence and characteristics of the polycystic ovary syndrome in overweight and obese women," Archives of Internal Medicine, vol. 166, no. 19, pp. 2081-2086, 2006.

[36] B. O. Yildiz, E. S. Knochenhauer, and R. Azziz, "Impact of obesity on the risk for polycystic ovary syndrome," Journal of Clinical Endocrinology and Metabolism, vol. 93, no. 1, pp. 162168, 2008.

[37] L. J. Moran, M. Noakes, P. M. Clifton, L. Tomlinson, C. Galletly, and R. J. Norman, "Dietary composition in restoring reproductive and metabolic physiology in overweight women with polycystic ovary syndrome," Journal of Clinical Endocrinology and Metabolism, vol. 88, no. 2, pp. 812-819, 2004.

[38] M. M. Huber-Buchholz, D. G. P. Carey, and R. J. Norman, "Restoration of reproductive potential by lifestyle modification in obese polycystic ovary syndrome: role of insulin sensitivity and luteinizing hormone," Journal of Clinical Endocrinology and Metabolism, vol. 84, no. 4, pp. 1470-1474, 1999.

[39] L. J. Moran, M. Noakes, P. M. Clifton, G. A. Wittert, G. Williams, and R. J. Norman, "Short-term meal replacements followed by dietary macronutrient restriction enhance weight loss in polycystic ovary syndrome," American Journal of Clinical Nutrition, vol. 84, no. 1, pp. 77-87, 2006.

[40] J. Holte, T. Bergh, C. Berne, L. Wide, and H. Lithell, "Restored insulin sensitivity but persistently increased early insulin secretion after weight loss in obese women with polycystic ovary syndrome," Journal of Clinical Endocrinology and Metabolism, vol. 80, no. 9, pp. 2586-2593, 1995.

[41] T. Sabuncu, M. Harma, M. Harma, Y. Nazligul, and F. Kilic, "Sibutramine has a positive effect on clinical and metabolic parameters in obese patients with polycystic ovary syndrome," Fertility and Sterility, vol. 80, no. 5, pp. 1199-1204, 2003.

[42] T. Sathyapalan, LI. W. Cho, E. S. Kilpatrick, A. M. Coady, and S. L. Atkin, "A comparison between rimonabant and metformin in reducing biochemical hyperandrogenaemia and insulin resistance in patients with polycystic ovary syndrome (PCOS): a randomized open-label parallel study," Clinical Endocrinology, vol. 69, no. 6, pp. 931-935, 2008.

[43] R. Guerciolini, "Mode of action of orlistat," International Journal of Obesity, vol. 21, supplement 3, pp. S12-S23, 1997.

[44] R. Padwal, S. K. Li, and D. C. W. Lau, "Long-term pharmacotherapy for overweight and obesity: a systematic review and meta-analysis of randomized controlled trials," International Journal of Obesity, vol. 27, no. 12, pp. 1437-1446, 2003.

[45] J. S. Torgerson, J. Hauptman, M. N. Boldrin, and L. Sjöström, "XENical in the prevention of diabetes in obese subjects (XENDOS) study: a randomized study of orlistat as an adjunct to lifestyle changes for the prevention of type 2 diabetes in obese patients," Diabetes Care, vol. 27, no. 1, pp. 155-161, 2004.

[46] V. Jayagopal, E. S. Kilpatrick, S. Holding, P. E. Jennings, and S. L. Atkin, "Orlistat is as beneficial as metformin in the treatment of polycystic ovarian syndrome," Journal of Clinical Endocrinology and Metabolism, vol. 90, no. 2, pp. 729-733, 2005.

[47] L. W. Cho, E. S. Kilpatrick, B. G. Keevil, A. M. Coady, and S. L. Atkin, "Effect of metformin, orlistat and pioglitazone treatment on mean insulin resistance and its biological variability in polycystic ovary syndrome," Clinical Endocrinology, vol. 70, no. 2, pp. 233-237, 2009.

[48] E. Diamanti-Kandarakis, I. Katsikis, C. Piperi, K. Alexandraki, and D. Panidis, "Effect of long-term orlistat treatment on serum levels of advanced glycation end-products in women with polycystic ovary syndrome," Clinical Endocrinology, vol. 66, no. 1, pp. 103-109, 2007.

[49] E. Diamanti-Kandarakis, C. D. Christakou, E. Kandaraki, and F. N. Economou, "Metformin: an old medication of new fashion: evolving new molecular mechanisms and clinical implications in polycystic ovary syndrome," European Journal of Endocrinology, vol. 162, no. 2, pp. 193-212, 2010.

[50] S. M. Setter, J. L. Iltz, J. Thams, and R. K. Campbell, "Metformin hydrochloride in the treatment of type 2 diabetes mellitus: a clinical review with a focus on dual therapy," Clinical Therapeutics, vol. 25, no. 12, pp. 2991-3026, 2003.

[51] R. Fleming, Z. E. Hopkinson, A. Michael Wallace, I. A. Greer, and N. Sattar, "Ovarian function and metabolic factors in women with oligomenorrhea treated with metformin in a randomized double blind placebo-controlled trial," Journal of Clinical Endocrinology and Metabolism, vol. 87, no. 2, pp. 569574, 2002.

[52] P. Moghetti, R. Castello, C. Negri et al., "Metformin effects on clinical features, endocrine and metabolic profiles, and insulin sensitivity in polycystic ovary syndrome: a randomized, double-blind, placebo-controlled 6-month trial, followed by open, long-term clinical evaluation," Journal of Clinical Endocrinology and Metabolism, vol. 85, no. 1, pp. 139-146, 2000.

[53] B. Trolle, A. Flyvbjerg, U. Kesmodel, and F. F. Lauszus, "Efficacy of metformin in obese and non-obese women with polycystic ovary syndrome: a randomized, double-blinded, placebo-controlled cross-over trial," Human Reproduction, vol. 22, no. 11, pp. 2967-2973, 2007.

[54] J. M. Lord, I. H. K. Flight, and R. J. Norman, "Metformin in polycystic ovary syndrome: systematic review and metaanalysis," British Medical Journal, vol. 327, no. 7421, pp. 951955, 2003.

[55] G. A. R. Maciel, J. M. Soares, E. L. Alves Da Motta, M. A. Haidar, G. Rodrigues De Lima, and E. C. Baracat, "Nonobese 
women with polycystic ovary syndrome respond better than obese women to treatment with metformin," Fertility and Sterility, vol. 81, no. 2, pp. 355-360, 2004.

[56] L. R. Harborne, N. Sattar, J. E. Norman, and R. Fleming, "Metformin and weight loss in obese women with polycystic ovary syndrome: comparison of doses," Journal of Clinical Endocrinology and Metabolism, vol. 90, no. 8, pp. 4593-4598, 2005.

[57] T. Sathyapalan, L. W. Cho, E. S. Kilpatrick, A. M. Coady, and S. L. Atkin, "Metformin maintains the weight loss and metabolic benefits following rimonabant treatment in obese women with polycystic ovary syndrome (PCOS)," Clinical Endocrinology, vol. 70, no. 1, pp. 124-128, 2009.

[58] H. C. S. Howlett and C. J. Bailey, "A risk-benefit assessment of metformin in type 2 diabetes mellitus," Drug Safety, vol. 20, no. 6, pp. 489-503, 1999.

[59] P. L. Brubaker and Y. Anini, "Direct and indirect mechanisms regulating secretion of glucagon-like peptide-1 and glucagonlike peptide-2," Canadian Journal of Physiology and Pharmacology, vol. 81, no. 11, pp. 1005-1012, 2003.

[60] D. J. Drucker, "The biology of incretin hormones," Cell Metabolism, vol. 3, no. 3, pp. 153-165, 2006.

[61] A. Mari, K. Degn, B. Brock, J. Rungby, E. L. E. Ferrannini, and O. Schmitz, "Effects of the long-acting human glucagonlike peptide- 1 analog liraglutide on $\beta$-cell function in normal living conditions," Diabetes Care, vol. 30, no. 8, pp. 2032-2033, 2007.

[62] B. Willms, J. Werner, J. J. Holst, C. Ørskov, W. Creutzfeldt, and M. A. Nauck, "Gastric emptying, glucose responses, and insulin secretion after a liquid test meal: effects of exogenous glucagon-like peptide-1 (GLP-1)-(7-36) amide in type 2 (noninsulin-dependent) diabetic patients," Journal of Clinical Endocrinology and Metabolism, vol. 81, no. 1, pp. 327-332, 1996.

[63] A. Flint, A. Raben, A. K. Ersbøll, J. J. Holst, and A. Astrup, "The effect of physiological levels of glucagon-like peptide-1 on appetite, gastric emptying, energy and substrate metabolism in obesity," International Journal of Obesity, vol. 25, no. 6, pp. 781-792, 2001.

[64] K. P. Kinzig, D. A. D’Alessio, and R. J. Seeley, “The diverse roles of specific GLP-1 receptors in the control of food intake and the response to visceral illness," Journal of Neuroscience, vol. 22, no. 23, pp. 10470-10476, 2002.

[65] K. Elkind-Hirsch, O. Marrioneaux, M. Bhushan, D. Vernor, and R. Bhushan, "Comparison of single and combined treatment with exenatide and metformin on menstrual cyclicity in overweight women with polycystic ovary syndrome," Journal of Clinical Endocrinology and Metabolism, vol. 93, no. 7, pp. 2670-2678, 2008.

[66] A. Astrup, S. Rössner, L. Van Gaal et al., "Effects of liraglutide in the treatment of obesity: a randomised, double-blind, placebo-controlled study," The Lancet, vol. 374, no. 9701, pp. 1606-1616, 2009.

[67] J. B. Buse, J. Rosenstock, G. Sesti et al., "Liraglutide once a day versus exenatide twice a day for type 2 diabetes: a 26week randomised, parallel-group, multinational, open-label trial (LEAD-6)," The Lancet, vol. 374, no. 9683, pp. 39-47, 2009.

[68] M. Parks and C. Rosebraugh, "Weighing risks and benefits of liraglutide-the FDA's review of a new antidiabetic therapy," New England Journal of Medicine, vol. 362, no. 9, pp. 774-777, 2010.

[69] G. M. Eid, D. R. Cottam, L. M. Velcu et al., "Effective treatment of polycystic ovarian syndrome with Roux-en-Y gastric bypass," Surgery for Obesity and Related Diseases, vol. 1, no. 2, pp. 77-80, 2005.

[70] H. F. Escobar-Morreale, J. I. Botella-Carretero, F. ÁlvarezBlasco, J. Sancho, and J. L. San Millán, "The polycystic ovary syndrome associated with morbid obesity may resolve after weight loss induced by bariatric surgery," Journal of Clinical Endocrinology and Metabolism, vol. 90, no. 12, pp. 6364-6369, 2005. 


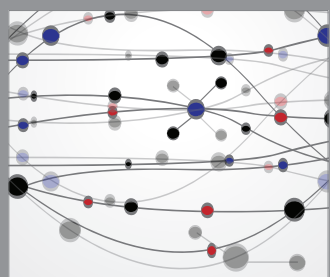

The Scientific World Journal
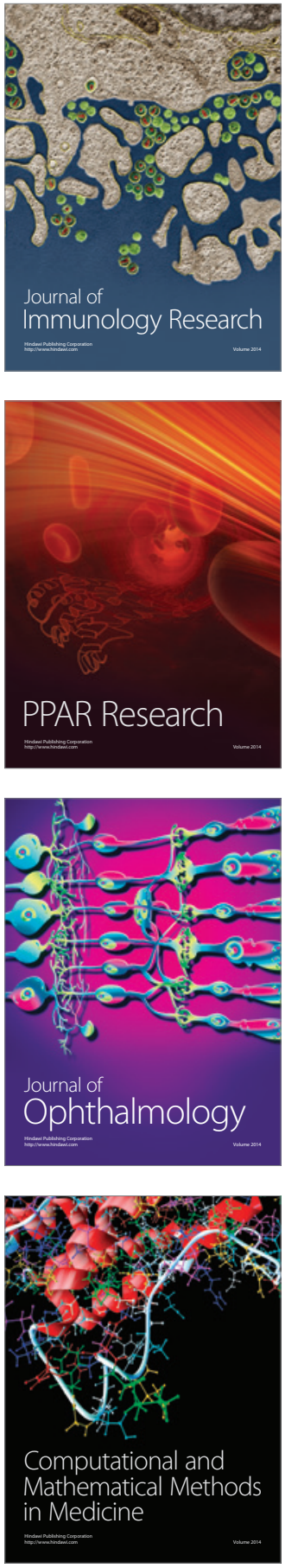

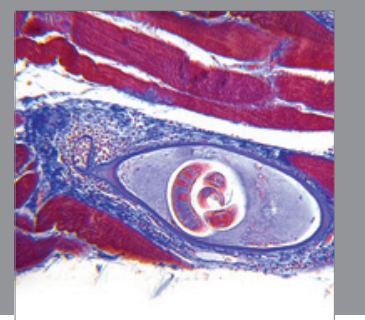

Gastroenterology

Research and Practice
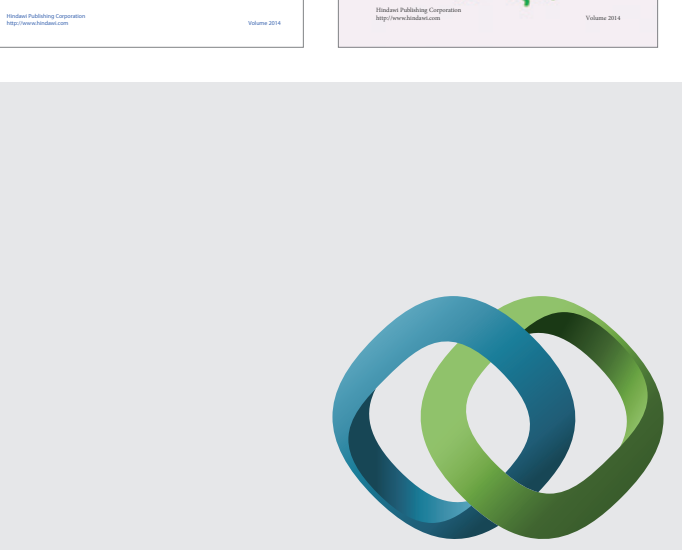

\section{Hindawi}

Submit your manuscripts at

http://www.hindawi.com
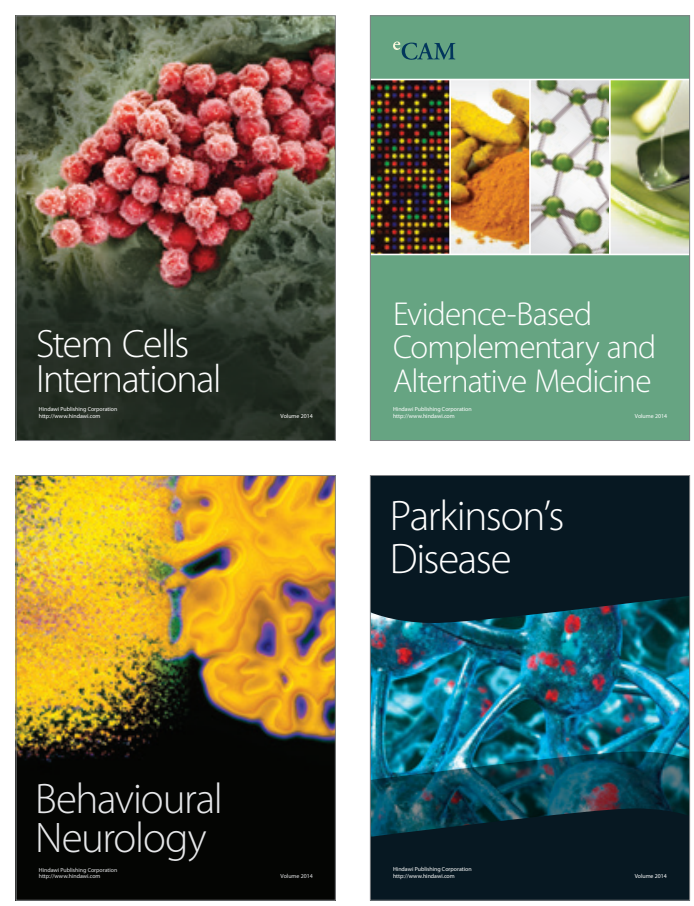

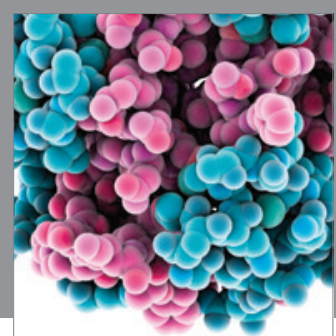

Journal of
Diabetes Research

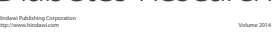

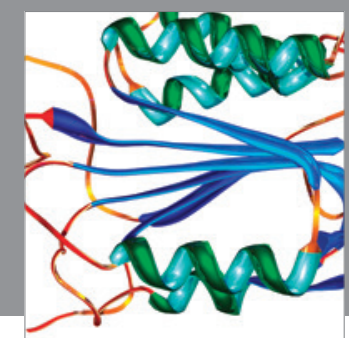

Disease Markers
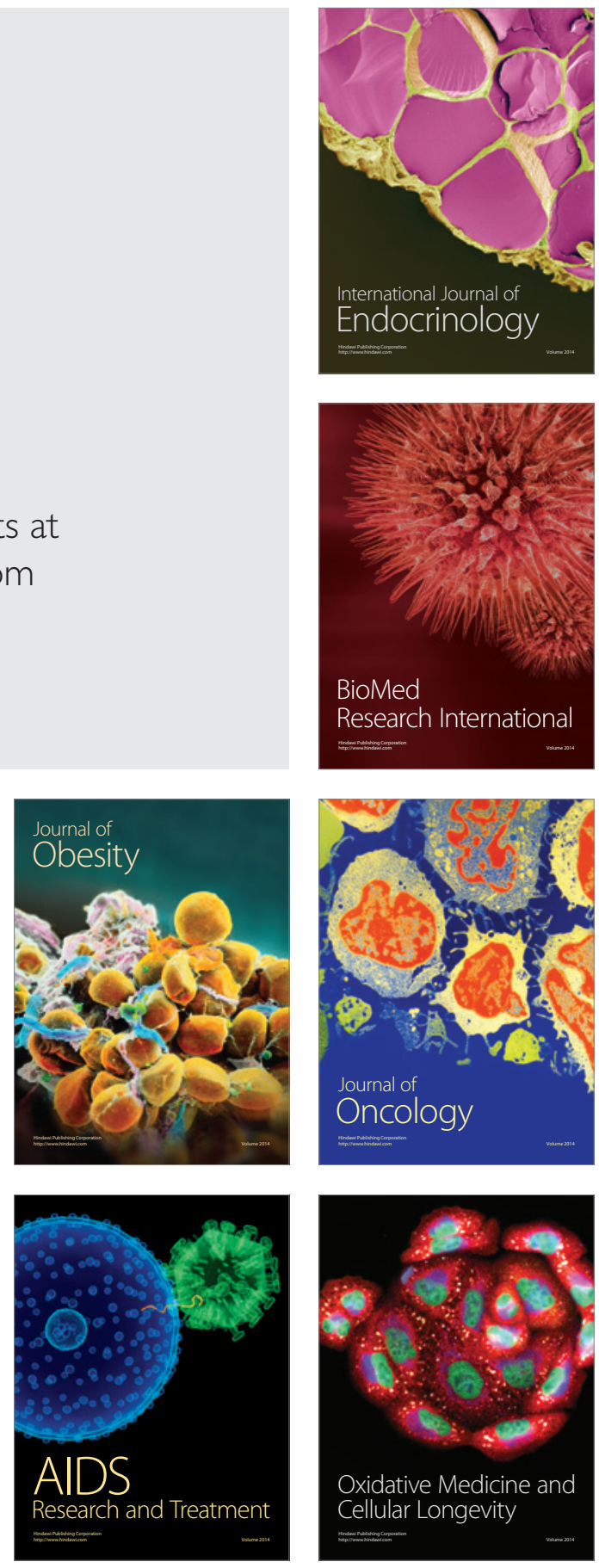